\title{
Article
}

\section{Selective Recovery of Precious Metals by a Novel Lignin Gel}

\author{
Kanjana Khunathai, Durga Parajuli, Chaitanya Raj Adhikari, Hidetaka Kawakita, Keisuke Ohto and \\ *Katsutoshi Inoue \\ *Department of Applied Chemistry, Saga University, 1-Honjo, Saga 840-8052, Japan \\ Masamitsu Funaoka \\ School of Bioresources, Mie University, 1515 Kimihama, Tsu, Mie 514-8507, Japan
}

(Manuscript submitted March 30, 2007; accepted June 2, 2007)

\begin{abstract}
For the recovery of precious metals like $\mathrm{Au}(\mathrm{III}), \mathrm{Pd}(\mathrm{II})$ and $\mathrm{Pt}(\mathrm{IV})$, dimethylamine immobilized crosslinked lignophenol gel, a novel lignin gel, was prepared from wood powder. Its adsorption behavior for $\mathrm{Au}(\mathrm{III})$, $\mathrm{Pt}(\mathrm{IV})$ and $\mathrm{Pd}(\mathrm{II})$ ions in hydrochloric acid medium was studied. The gel was found to adsorb all three precious metals quantitatively irrespective of the concentration of hydrochloric acid while it was found to be inert towards other base metals such as $\mathrm{Cu}(\mathrm{II}), \mathrm{Zn}(\mathrm{II}), \mathrm{Ni}(\mathrm{II})$, and $\mathrm{Fe}(\mathrm{III})$. This kind of performance of the novel gel can be promising for the low cost recovery of precious metals from electrical and electronic wastes by utilizing nature friendly materials.
\end{abstract}

Keywords: precious metal, lignophenol, dimethylamine, adsorption

\section{Introduction}

Possessing many interesting physical as well as chemical properties, precious metals are being utilized in petrochemicals, medicine, photography, and in recent decades extensively in electrical and electronic products [1]. High demand and limited resources are responsible for their impacts in economics. For the sustainability of the environment and the economy, concerns must be given in the recovery and reuse of valuable resources. In other words, innovative methods of recovering precious metals from piles of electrical and electronic wastes (e-wastes) should be developed. Recycling of homogenous wastes is a technical and economic challenge. Therefore, the effective recovery of precious metals from industrial waste is very important mainly from the viewpoint of sustainability of resources and environment.

Solvent extraction techniques are regarded as highly useful methods in the recovery and purification of precious metals from chloride solutions. Alternatively, solid-liquid extraction has been applied mainly to very dilute solutions [2]. Consequently, the adsorptive recovery seems to be the most suitable method for the precious metals at low concentration due to the cost and efficiency factors [3].

Recently, the use of biomacromolecules is emerging as an important component to produce green materials with unique physical and functional properties [5-6]. Among these, lignin, a three-dimensional polymer consisting of phenylpropanoid units mainly of aryl and alkyl ether, is highly available biowaste [4]. 
Although the complex structure of lignin makes it difficult to process and modify, the design of lignin-based polymer called lignophenol and its various derivatives are found to be effective in the recovery of metal ion [8-10].

In this study, wood powder obtained from the lumbering of Japanese cedar trees in Miyazaki, Japan, was used as a feed material to prepare crosslinked lignophenol gel. Since crosslinked lignophenol gel is found to be selective only for $\mathrm{Au}(\mathrm{III})$, functional group of dimethylamine was introduce to obtain dimethylamine type of crosslinked lignophenol gel, abbreviated here after as DiMA-lignin, for the selective recovery of not only gold but also other precious metals like palladium and platinum which are known to have high affinity towards the amine functional groups. The effects of various experimental conditions on the adsorption properties of the gel for $\mathrm{Au}(\mathrm{III}), \mathrm{Pd}(\mathrm{II})$, and $\mathrm{Pt}(\mathrm{IV})$ ions were investigated.

\section{Experimental}

\subsection{Materials}

Preparation of crosslinked lignophenol: Crosslinked lignophenol gel was prepared by immobilizing phenol to the lignin network of waste wood according to the method described in the previous papers[7-9].

Preparation of dimethylamine type of crosslinked lignophenol: Dimethylamine modified crosslinked lignophenol gel, DiMA-lignin, was prepared according to Scheme 1 . In a 3-necked flask, $5 \mathrm{~g}$ crosslinked lignophenol was taken together with $200 \mathrm{ml}$ pyridine and was kept in an ice bath. Thirty milliliter of thionyl chloride $\left(\mathrm{SOCl}_{2}\right)$ was added drop wise to the mixture with stirring for about $1 \mathrm{~h}$. The mixture was further stirred continuously for $5 \mathrm{~h}$ at $70^{\circ} \mathrm{C}$. The chlorinated product was washed with distilled water and dried for $5 \mathrm{~h}$ at $50{ }^{\circ} \mathrm{C}$ in a convection oven. The chlorinated product of crosslinked lignophenol was added with $50 \mathrm{ml}$ of $50 \%$ dimethylamine solution and $10 \mathrm{ml}$ of $37 \%$ formaldehyde solution and heated at $90{ }^{\circ} \mathrm{C}$ with continuous stirring for $3 \mathrm{~h}$. The product was filtered and washed with $0.1 M\left(M=\mathrm{mol} / \mathrm{dm}^{3}\right)$ sodium hydroxide, $0.1 M$ hydrochloric acid and finally converted to chloride form by washing with $0.1 \mathrm{M} \mathrm{NaCl}$ solution. Then the product was dried for $5 h$ at $60^{\circ} \mathrm{C}$ and sieved to 150 mesh size.

Reagents and solutions: Analytical grade chloride salts of copper, iron, palladium, nickel and zinc were used to prepare the test solution. Also, analytical grade $\mathrm{HAuCl}_{4} \cdot 4 \mathrm{H}_{2} \mathrm{O}$ and $\mathrm{H}_{2} \mathrm{PtCl}_{6} \cdot 6 \mathrm{H}_{2} \mathrm{O}$ were used to prepare the test solutions of gold and platinum, respectively.

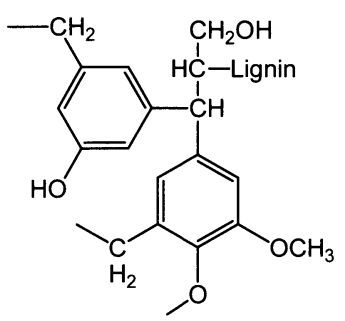

Crosslinked Lignophenol

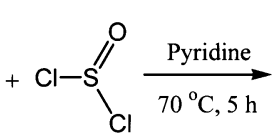

Chlorinated Crosslinked Lignophenol

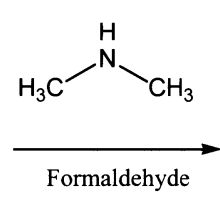

$90{ }^{\circ} \mathrm{C}, 3 \mathrm{~h}$

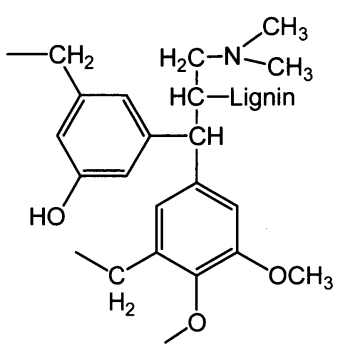

DiMA-lignin

Scheme 1. Preparation of dimethylamine crosslinked lignophenol (DiMA-lignin)

\subsection{Adsorption studies}

All adsorption equilibrium experiments for $\mathrm{Au}(\mathrm{III}), \mathrm{Pd}(\mathrm{II}), \mathrm{Pt}(\mathrm{IV}), \mathrm{Cu}(\mathrm{II}), \mathrm{Zn}(\mathrm{II}), \mathrm{Fe}(\mathrm{III})$ and $\mathrm{Ni}(\mathrm{II})$ were conducted batch wise in a thermostated shaker maintained at $30^{\circ} \mathrm{C}$ for $50 \mathrm{~h}$ by using $20 \mathrm{mg}$ of gel, $15 \mathrm{ml}$ of test 
solution at varying hydrochloric acid concentration. Adsorption kinetics was measured by taking $10 \mathrm{ml}$ of $0.2 \mathrm{mM}$ test solutions prepared in $0.5 \mathrm{M}$ hydrochloric acid. The metal concentration in the solution was measured by using an ICP/AES (Shimadzu model ICPS-8100) and an atomic absorption spectrophotometer (Shimadzu model AA-6650).

\section{Results and Discussion}

\subsection{Elemental analysis}

In order to identify the degree of immobilization of dimethylamine onto the gel, elemental analysis was performed. As shows in Table 1, as much as $100 \%$ functionalization, calculated according to the Eq. 1. was observed. Compared with immobilized by primary amine and diethylamine [8], higher degree of amination was achieved in this study. This result proved high accomplishment of the amination reaction of dimethylamine to active side chain and some of hydroxyl groups were attached with dimethylamine as well. In addition, the functional group density in the gel of DiMA-lignin was calculated as $3.32 \mathrm{~mol} / \mathrm{kg}$.

$\%$ immobilization $=[($ observed wt $\%$ of nitrogen $) /($ calculated wt $\%$ of nitrogen $)] \times 100$

Table 1 Elemental composition of DiMA-lignin

\begin{tabular}{lccc}
\hline Elements & $\mathrm{H}$ & $\mathrm{C}$ & $\mathrm{N}$ \\
\hline Calculated \% & 6.84 & 74.05 & 4.32 \\
Observed \% & 4.45 & 57.54 & 4.65 \\
\hline
\end{tabular}

\subsection{Kinetics of adsorption}

The kinetics of adsorption of $\mathrm{Au}(\mathrm{III}), \mathrm{Pd}(\mathrm{II})$, and Pt(IV) on DiMA-lignin is shown in Fig. 1. As evident from the figure, the equilibrium for gold was attained within an hour whereas it took comparatively longer time of about 5 $h$ for $\mathrm{Pd}(\mathrm{II})$ and $\mathrm{Pt}(\mathrm{IV})$. Consequently, subsequent adsorption tests were conducted by shaking for $50 h$ in order to reach a complete equilibrium.

\subsection{Adsorption behavior}

Figure 2 shows the \%adsorption of various precious and base metal ions on the DiMA- lignin gel from hydrochloric acid at varying concentrations of hydrochloric acid. This figure exhibited the quantitative adsorption of precious metal ions, $\mathrm{Au}(\mathrm{III}), \mathrm{Pd}(\mathrm{II})$, and $\mathrm{Pt}(\mathrm{IV})$, irrespective of hydrochloric acid concentration. But, under the same condition, base metals like $\mathrm{Cu}(\mathrm{II}), \mathrm{Fe}(\mathrm{III}), \mathrm{Ni}(\mathrm{II})$

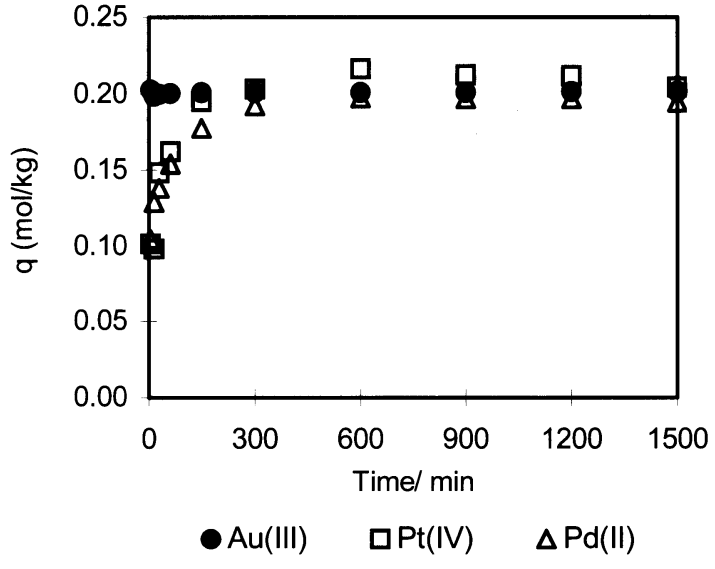

Fig. 1 Amount of adsorption of $\mathrm{Au}(\mathrm{III}), \mathrm{Pd}(\mathrm{II})$ and Pt(IV) on DiMA-lignin vs. shaking time. Initial concentration of metal ions $=0.2 \mathrm{mM}$, wt of gel $=$ $10 \mathrm{mg}$, vol. of solution $=10 \mathrm{ml}$, and $[\mathrm{HCl}]=0.5$ and $\mathrm{Zn}$ (II) were not adsorbed by the gel. In our previous study crosslinked lignophenol gel was found to be able to adsorb only $\mathrm{Au}(\mathrm{III})$ [7-9]. The aminated lignophenol gels EN-lignin and PA-lignin have shown some affinity also for Pd(II) and Pt(IV). This result is similar to the previous results in sense of the selectivity for precious metals over the base metals but it is better for quantitatively adsorbing all of $\mathrm{Au}(\mathrm{III}), \mathrm{Pd}(\mathrm{II})$, and $\mathrm{Pt}(\mathrm{IV})$ even from the 
low concentration region like $0.2 \mathrm{mM}$. High functional group density resulted by complete immobilization of crosslinked lignophenol to DiMA-lignin resulted in the competitive adsorption of precious metals against base metals at any concentration region of hydrochloric acid.

Moreover, the formation of gold particle was clearly observed in case of gold adsorption. This observation confirmed the fact that the modified crosslinked lignophenol gel, DiMA-lignin, retains the property of reducing trivalent gold ions in aqueous chloride solution to metallic gold during adsorption. The digital micrograph of the gel taken after the adsorption of gold is shown in Fig. 3. The black color of the gel became golden as a result of the deposition of gold particles.

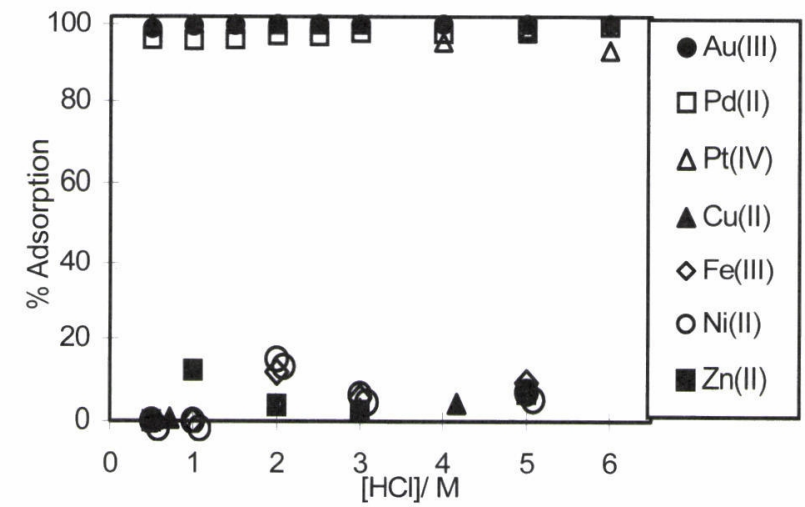

Fig. 2 Adsorption various metal ions on DiMA-lignin as a function of hydrochloric acid concentration. Initial metal concentration $=0.2 \mathrm{mM}$, wt. of gel $=20 \mathrm{mg}$, shaking time $50 \mathrm{~h}$, and temperature $=30^{\circ} \mathrm{C}$.

This study has shown the potential application of wood derived novel lignin gel for the recovery of $\mathrm{Au}(\mathrm{III}), \mathrm{Pd}(\mathrm{II})$ and $\mathrm{Pt}(\mathrm{IV})$. As DiMA-lignin is found to be highly selective for all these precious metal ions in a wide range of hydrochloric acid concentration, it seems feasible to apply for recovery of precious metal from industrial effluent.

\section{Acknowledgement}

This study was financially supported in part by Grant- in- Aid for Scientific Research by JSPS (No. 19560757).

\section{References}

1) S. Doker, S. Malci, M. Dogan and B. Salih, Anal. Chim. Acta, 553, 73-82 (2005).

2) M. Iglesias, E. Antico and V. Salvado, Anal. Chim. Acta., 381, 61-67 (1999).

3) H. Ma, X. Liao, X. Liu and B. Shi, J. Membr. Sci., 278, 373-380 (2006).

4) P. Wunning, "Biopolymers: Lignin, Humic Substances and Coal" (Eds. M. Hofricher and A. Steinbuchel), Wiley-VCH, New York (2001), pp 118- 126.

5) M. Funaoka, Polym. Int .47, 277-290 (1998).

6) T. Ogata and Y. Nagano, Water Res., 39, 4281-4286 (2005).

7) D. Parajuli, C. R. Adhikari, M. Kuriyama, H. Kawakita, K. Ohto, K. Inoue and M. Funaoka, Ind. Eng. Chem. Res., 45, 8-14 (2006).

8) D. Parajuli, H. Kawakita, K. Inoue and M. Funaoka, Ind. Eng. Chem. Res., 45, 6405-6412 (2006).

9) D. Parajuli, K. Inoue, M. Kuriyama, M. Funaoka and K. Makino, Chem. Lett., 34, 34-35 (2005). 